\title{
Sudden Cardiac Death with Clozapine and Lorazepam Combination
}

\author{
Sriram Ramaswamy \\ Creighton-Nebraska Psychiatry Residency Program
}

\author{
Susan J. Boust \\ University of Nebraska Medical Center
}

Prizada S. Sattar

Creighton University; Omaha Veterans Affairs Medical Center

Subhash C. Bhatia

Creighton University; Omaha Veterans Affairs Medical Center

Frederick Petty

Creighton University: Omaha Veterans Affairs Medical Center

Follow this and additional works at: https://jdc.jefferson.edu/jeffjpsychiatry

Part of the Psychiatry Commons

Let us know how access to this document benefits you

\section{Recommended Citation}

Ramaswamy, Sriram; Boust, Susan J.; Sattar, Prizada S.; Bhatia, Subhash C.; and Petty, Frederick (2005) "Sudden Cardiac Death with Clozapine and Lorazepam Combination," Jefferson Journal of Psychiatry. Vol. 19 : Iss. 1 , Article 6.

DOI: https://doi.org/10.29046/JJP.019.1.005

Available at: https://jdc.jefferson.edu/jeffjpsychiatry/vol19/iss1/6

This Article is brought to you for free and open access by the Jefferson Digital Commons. The Jefferson Digital Commons is a service of Thomas Jefferson University's Center for Teaching and Learning (CTL). The Commons is a showcase for Jefferson books and journals, peer-reviewed scholarly publications, unique historical collections from the University archives, and teaching tools. The Jefferson Digital Commons allows researchers and interested readers anywhere in the world to learn about and keep up to date with Jefferson scholarship. This article has been accepted for inclusion in Jefferson Journal of Psychiatry by an authorized administrator of the Jefferson Digital Commons. For more information, please contact: JeffersonDigitalCommons@jefferson.edu. 


\title{
Sudden Cardiac Death with Clozapine and Lorazepam Combination
}

\section{Sriram Ramaswamy M.D. a, Susan J. Boust M.D.b , Pirzada S. Sattar, M.D.c, Subhash C. Bhatia M.D. ${ }^{\text {, }}$, and Frederick Petty, M.D., Ph.D. ${ }^{\text {e }}$}

\begin{abstract}
OBJECTIVE: To report a case of sudden cardiac death in a patient taking a combination of clozapine and lorazepam. CASE SUMMARY: A 31-year-old white man with schizophrenia was found dead at his apartment. His medication regimen included clozapine $500 \mathrm{mg}$ at bed time, lorazepam $0.5 \mathrm{mg}$ three times daily and levothyroxine $75 \mathrm{mcg}$ once a day. Autopsy studies revealed cardiac hypertrophy, pulmonary congestion and edema. DISCUSSION: Clozapine therapy may cause cardiomyopathy and reduction in heart rate variability $(H R V)$ indices. Benzodiazepines can reduce vagal tone and increase sympathetic activity. This combination can have an enhanced potential for sudden cardiac death. CONCLUSIONS: Clozapineinduced cardiomyopathy and arrhythmias from clozapine and/or lorazepam use may have contributed to this man's death.
\end{abstract}

Key Words: clozapine, sudden death, lorazepam

\section{Introduction}

Sudden cardiac death (SCD) is defined as an unexpected death due to cardiac causes, occurring in a short span of time, generally within one hour of symptom onset in a person with known or unknown cardiac disease with no previously diagnosed fatal condition.

Epidemiological studies of schizophrenic patients suggest an increased incidence of cardiovascular mortality $(1,2)$, which has been linked to the use of antipsychotic medications $(3,4)$. It is well established that some antipsychotic drugs prolong the QT interval, and cause torsades de pointes (5). An increased risk of sudden cardiac death may be related to the dose-related effects of antipsychotic medications on cardiac electrophysiology. We report a case of presumed sudden cardiac death in a middle-aged male possibly due to the combination of clozapine and lorazepam.

\section{Case report}

Patient A was a 31-year-old Caucasian male with a diagnosis of schizophrenia, undifferentiated type based on DSM-IV criteria. He had a history of multiple psychiatric hospitalizations due to non-compliance with

aPGY-IV \& Chief Resident, Creighton - Nebraska Psychiatry Residency Program.

bAssociate Professor of Psychiatry, University of Nebraska Medical Center \& Staff Psychiatrist ACT Program.

cAssistant Professor of Psychiatry, Creighton University and Staff Psychiatrist, Omaha Veterans Affairs Medical Center.

dProfessor of Psychiatry and Vice Chair for Clinical Affairs, Creighton University and Chief of Mental Health, Omaha Veterans Affairs Medical Center.

eProfessor of Psychiatry and Vice Chair for Research, Creighton University \& Associate Chief Department of Mental Health, Omaha Veterans Affairs

Medical Center.

Please address correspondence to Dr. Sriram Ramaswamy, M. D., Creighton - Nebraska Psychiatry Residency Program, 3528 Dodge Street Omaha, NE

68131, Tel: (402) 345-8828, Fax: (402) 345-8815, Email: sramaswamy@creighton.edu 
medications. Prior to admission, the patient was receiving olanzapine $15 \mathrm{mg}$ twice a day, haloperidol $10 \mathrm{mg}$ at bedtime, lorazepam $0.5 \mathrm{mg}$ three times a day and benztropine mesylate $1 \mathrm{mg}$ three times a day. He was also on levothyroxine $75 \mathrm{mcg}$ once a day for recently diagnosed hypothyroidism. In addition, he had a history of hypertension, which was not being treated because his blood pressure was within normal limits. His laboratory workup was essentially normal. No electrocardiogram was done during the admission. His family history was negative for cardiovascular disease or sudden death. The patient admitted to occasional cannabis use and there was no history of alcohol use.

It was observed during an outpatient appointment that the patient continued to show signs of psychosis. He was then switched from olanzapine to risperidone, but his symptoms persisted. Therefore, clozapine $50 \mathrm{mg}$ at bedtime was initiated after obtaining consent and following relevant medical workup. The dose of clozapine was gradually titrated to $500 \mathrm{mg}$ at bedtime; risperidone and haloperidol were discontinued, while lorazepam $0.5 \mathrm{mg}$ three times a day, and levothyroxine $75 \mathrm{mcg}$ once daily were continued. With this combination of medications administered under supervision of his case manager, the patient did well. He showed decreased aggression and improved organization of speech and thought process. However, he continued to exhibit some social withdrawal. The patient was prescribed clozapine for approximately one year. Clozapine levels obtained at regular intervals were within the recommended range for optimal clinical response (6). The $\mathrm{CBC}$ with differential, done at suggested intervals, was within normal limits. (See Table 1)

Table 1

\begin{tabular}{|c|c|c|}
\hline \multicolumn{3}{|c|}{ Serial Clozapine and Norclozapine Levels } \\
\hline CLOZAPINE & NORCLOZAPINE & COMBINED \\
\hline $139 \mathrm{ng} / \mathrm{L}$ & $162 \mathrm{ng} / \mathrm{L}$ & $310 \mathrm{ng} / \mathrm{l}$ \\
\hline $246 \mathrm{ng} / \mathrm{L}$ & $132 \mathrm{ng} / \mathrm{L} 378 \mathrm{ng} / \mathrm{L}$ & \\
\hline $175 \mathrm{ng} / \mathrm{L}$ & $172 \mathrm{ng} / \mathrm{L}$ & $347 \mathrm{ng} / \mathrm{L}$ \\
\hline $173 \mathrm{ng} / \mathrm{L}$ & $140 \mathrm{ng} / \mathrm{L}$ & $313 \mathrm{ng} / \mathrm{L}$ \\
\hline
\end{tabular}

During routine follow up home visits on two successive days by his caseworker, the patient failed to answer the doorbell. The door was forcibly opened; the patient was found lying slumped in a chair and was unresponsive. Emergency Medical Services was called and the patient was declared dead. A day's supply of his medications was found near the entry door.

The post-mortem toxicology studies were negative for amphetamines, cocaine, cannabis, benzodiazepines, methadone, opiates, phencyclidine, propoxyphene and barbiturates. The blood ethanol level was less than $0.010 \mathrm{~g} / 100 \mathrm{ml}$. The blood immunoassay detected clozapine and nicotine; both blood clozapine and norclozapine concentrations were less than $100 \mathrm{ng} / \mathrm{ml}$ each.

Gross autopsy findings showed a middle-aged male measuring 69.5 inches in length, 250 pounds in weight. There was no evidence of trauma nor epidural, subdural or intracranial hemorrhage. There were no foreign bodies in the larynx or in the tracheobronchial tree and no pills or capsule fragments were identified in the stomach contents.

There was cardiac hypertrophy, with the heart weighing 480 grams (normal being up to 375 grams). The free wall of the left ventricle and the interventricular septum measured $15 \mathrm{~mm}$ in thickness (normal $10 \mathrm{~mm}$ ). The right ventricular wall measured $4 \mathrm{~mm}$ in thickness (normal $10 \mathrm{~mm}$ ). There was moderate dilatation of all four chambers of heart. Final anatomic diagnoses were: 1) cardiac hypertrophy, 2) coronary atherosclerosis with 0-25\% narrowing of the left anterior descending coronary artery, 3) moderate four chamber dilatation of heart, 4) pulmonary congestion and edema, 5) benign cortical cyst left kidney, 6) congestion of abdominal viscera. The final cause of death was hypertensive heart disease with the terminal event most likely being an acute cardiac arrhythmia. 


\section{Discussion}

Clozapine, a tricyclic dibenzodiazepine derivative, is classified as an atypical antipsychotic. It is indicated for the management of treatment resistant, severely ill schizophrenic patients. Benefits of clozapine include lack of extrapyramidal side effects and the reduction of negative symptoms (7). A rare side effect of clonazapine is agranulocytosis, with a rate of $1.3 \%(8)$. Well-documented cardiovascular effects of clozapine include orthostatic hypotension (9\%), tachycardia (25\%) and electrocardiogram changes (1\%) (8).

New onset EKG changes consisting of premature ventricular contractions have been reported with clozapine therapy (9). Clozapine has been demonstrated to cause concentration dependent prolongation of the QT interval in isolated feline hearts (10). The data suggest that clozapine may also have proarrhythmic activity and could potentially give rise to life threatening arrhythmias particularly with overdose, either directly or in combination with a coexisting myocarditis. The low postmortem clozapine concentration in our patient could be explained by the missed doses of clozapine found in the patient's apartment. However, the blood clozapine levels done at serial intervals and also the one closest to the time of his death (within a month) were therapeutic. Medication compliance was also ensured by supervised administration of his medications.

Most sudden cardiac death is attributed to ventricular tachycardia and or ventricular fibrillation with the autonomic nervous system playing an important role. One reliable measure quantifying autonomic nervous system activity is the heart rate variability (HRV) (11). In one study, clozapine was shown to disrupt autonomic neurocardiac function by reducing HRV in seven out of 13 patients receiving the drug (12). Reduced HRV has been shown to increase the risk of sudden death (13). In our patient we did not have an EKG or 24 hour Holter monitoring to substantiate this cause.

Lorazepam may have significant vagolytic effects as manifested by the increase in heart rate and decreases in HPV (heart period variability indices), as demonstrated by a double blind randomized placebo controlled study in healthy volunteers (14). Another study examining the short-term effects of intravenous application of benzodiazepines suggested that they cause a reduction of central vagal tone. They may also decrease the cardiac pacemaker activity directly (15). The likely mechanism through which benzodiazepines produce vagolytic effects is probably through their interaction with the gamma-aminobutyric acid A-receptor chloride ion channel complex (16). An imbalance in cardiac sympathetic autonomic tone in favor of high sympathetic activity increases the risk for cardiac morbidity or mortality in patients with preexisting cardiac disease (17), even in patients without structural heart disease (18).

The effects of the combination of antipsychotics and benzodiazepines on the autonomic neurocardiac function (ANR) have not yet been systematically investigated. Furthermore, it is not known whether the combination of an antipsychotic and a benzodiazepine increases the risk for cardiac arrhythmias and sudden death, as compared to the risks associated with the individual agents. It is possible in the case presented, that clozapine and lorazepam caused his death. This theory would be supported if an autopsy showed pathological cardiac findings or left ventricular and interventricular septal hypertrophy. In our case, the patient was found to have left ventricular hypertrophy, making it plausible that the combination of clozapine and lorazepam caused his death. It cannot be ignored that our patient was diagnosed with hypertension. However, he was normotensive prior to his death, and therefore, not taking any antihypertensive medication. Furthermore, studies have shown that there is no correlation of LVH in individuals with normal blood pressure versus elevated blood pressure in patients younger than 65 (19).

A literature search on MEDLINE from 1966 through 2002 showed case reports of sudden death in patients treated concurrently with clozapine and benzodiazepine (20), clozapine and haloperidol (21) and clozapine and sertraline (22). The case report with clozapine and sertraline (22) was attributed to clozapine induced cardiomyopathy without evidence of myocarditis. This search revealed no reports of sudden death with lorazepam monotherapy. Clozapine is metabolized by the cytochrome enzyme system; CYP 450 1A2, 2C19 and 34A (8). Lorazepam is metabolized via the glucuronidation pathway, so there is no major drug interaction between the two drugs via the CYP-450 system. Two cases have been reported in which concomitant 
use of clozapine and lorazepam resulted in marked sedation, excessive salivation, and ataxia (23), and caution is advised when administering clozapine with a benzodiazepine (8). In the case report where there was sudden death after intravenous administration of lorazepam to a patient treated with clozapine, the autopsy did not show any pathological findings and the death was presumed due to respiratory failure.

Our patient was taking lorazepam and clozapine at the time of death and the autopsy showed evidence of cardiomegaly. Use of the Naranjo ADR Probability Scale (24) indicated a possible relationship between sudden cardiac death and combined therapy with lorazepam and clozapine in this patient. To our knowledge this is the first report of sudden cardiac death in a patient treated with a combination of clozapine and lorazepam with pathological autopsy findings.

\section{Summary}

This case report is not conclusive in proving a direct relationship between combined clozapine and lorazepam use and sudden death. However it points in that direction. There is evidence to suggest that clozapine therapy may cause cardiomyopathy, myocarditis, and reduction in heart rate variability (HRV) indices as well as anticholinergic effects resulting in proarrthymogenic outcomes. Moreover benzodiazepines can cause reduction in vagal tone with subsequent shifting of neurocardiac balance in favor of sympathetic activity. This effect can enhance potential for cardiac death in a patient taking a combination of clozapine and lorazepam. There may be other unexplained effects of this combination leading to this fatal complication. In any case, it is important that the prescribing clinicians be aware of the potential for a sudden cardiac death with the combination of clozapine and lorazepam therapy.

\section{REFERENCES:}

1. Allebeck P, Wistedt B. Mortality in schizophrenia: a ten-year follow-up based on the Stockholm County Inpatient Register. Arch Gen Psychiatry 1986; 43(7): 650-3.

2. Newman SC, Bland RC. Mortality in a cohort of patients with schizophrenia: a record linkage study. Can J Psychiatry 1991; 36(4): 239-45.

3. Ray WA, Meredith S, Thapa PB, et al. Antpsychotics and the risk of sudden cardiac death. Arch Gen Psychiatry 2001; 58(12): 1161-7.

4. Ruschena D, Mullen PE, Burgess P, et al. Sudden death in psychiatric patients. British Journal of Psychiatry 1998; 172: 331-6.

5. Zarate CA Jr, Patel J. Sudden cardiac death and antipsychotic drugs: do we know enough? Arch Gen Psychiatry 2001; 58(12): 1168-71.

6. Kronig MH, Munne RA, Szymanski S, et al. Plasma clozapine levels and clinical response for treatment refractory schizophrenic patients. Am J Psychiatry 1995; 152(2): 179-82.

7. Bablenis E, Weber SS, Wagner RL. Clozapine: a novel antipsychotic agent. DICP 1989; 23(2): 109-15.

8. Thompson Healthcare. Physician's Desk Reference, 57th edition. Montvale, NJ, 2003; 2237-40.

9. Aronowitz JS, Umbricht DS, Safferman AZ. Clozapine and new onset ECG abnormalities (letter). Psychosomatics 1995; 36(1): 82-3. 
10. Drici MD, Wang WX, Liu X, et al. Prolongation of QT interval in isolated feline hearts by antipsychotic drugs. J Clin Psychopharmacol 1998; 18(6): 477-81.

11. Akselrod S, Gordon D, Ubel FA, et al. Power spectral analysis of heart rate fluctuation: a quantitative probe of beat to beat cardiovascular control. Science 1981; 10; 213(4504): 220-2.

12. Agelink MW, Majewski T, Wurthmann C, et al. Effects of newer atypical antipsychotics on autonomic neurocardiac function: a comparison between amisulpride, olanzapine, sertindole, and clozapine. J Clin Psychopharmacol 2001; 21(1): 8-13.

13. Algra A, Tijssen JG, Roelandt JR, et al. Heart rate variability from 24 hour electrocardiography and the 2-year risk for sudden death. Circulation 1993; 88(1): 80-5.

14. Vogel LR, Muskin PR, Collins ED, et al. Lorazepam reduces cardiac vagal modulation in normal subjects. J Clin Psychopharmacol 1996; 16(6): 449-53.

15. Agelink MW, Majewski TB, Andrich J, et al. Short-term effects of intravenous benzodiazepines on autonomic neurocardiac regulation in humans: a comparison between midazolam, diazepam, and lorazepam. Crit Care Med 2002; 30(5): 997-1006.

16. DiMicco JA. Evidence for control of cardiac vagal tone by benzodiazepine receptors. Neuropharmacology 1987; 26(6): 553-9.

17. Lanza GA, Pedrotti P, Rebuzzi AG, et al. Usefulness of the addition of heart rate variability to Holter monitoring in predicting in-hospital cardiac events in patients with unstable angina pectoris. American Journal of Cardiology 1997; 80(3): 263-7.

18. Molgaard H, Sorensen KE, Bjerregaard P. Attenuated 24-hr heart rate variability in apparently healthy subjects, subsequently suffering sudden cardiac death. Clin Auton Res 1991; 1(3): 233-7.

19. Tingleff J, Munch M, Jakobsen TJ, et al. Prevalence of left ventricular hypertrophy in a hypertensive population. European Heart Journal 1996; 17(1): 143-9.

20. Klimke A, Klieser E. Sudden death after intravenous administration of lorazepam in a patient treated with clozapine. American Journal of Psychiatry 1994; 15(5): 780.

21. Grohmann R, Ruther E, Sassim N, et al. Adverse effects of clozapine. Psychopharmacology (Berl) 1989; 99 Suppl: S101-4.

22. Hoehns JD, Fouts MM, Kelly MW, et al. Sudden cardiac death with clozapine and sertraline combination. Ann Pharmacother 2001; 35(7-8): 862-6.

23. Cobb CD, Anderson CB \& Seidel DR. Possible interaction between clozapine and lorazepam (letter). Am J Psychiatry 1991; 148(11): 1606-7.

24. Naranjo CA, Busto U, Sellers EM, et al. A method for estimating the probability of adverse drug reactions. Clin Pharmacol Ther 1981; 30:239-45. 